PURBawIdya: Jurnal Penelitian dan Pengembangan Arkeologi p-ISSN: 2252-3758, e-ISSN: 2528-3618 Akreditasi LIPI No. 695/Akred/ P2MI-LIPI/07/2015

Vol. 7(1), Juni 2018, pp 35 - 52 DOI: https://doi.org/10.24164/pw.v7i1.255

\title{
REKONSTRUKSI ARSITEKTUR KOMPLEKS KADIPATEN DI KAMPUNG PANEMBAHAN, KECAMATAN KRATON, YOGYAKARTA
}

\author{
Architectural Reconstruction of Kadipaten District in Kampung Panembahan, \\ Kecamatan Kraton, Yogyakarta
}

\author{
Wulandari Retnaningtiyas \\ Balai Arkeologi Jawa Barat \\ Jalan Raya Cinunuk Km. 17 Cileunyi Bandung \\ E-mail: wulan.retnaningtiyas@gmail.com \\ Naskah diterima 2 Maret 2018 — Revisi terakhir 28 Juni 2018 \\ Disetujui terbit 10 Juli 2018 - Tersedia secara online 1 Agustus 2018
}

\begin{abstract}
Kadipaten, the residence of Pangeran Adipati Anom is an important district/ sub-complex within Kraton Yogyakarta. As today, the toponym of Kadipaten can be found in the west side of kraton, although some historical accounts noted something different. Previously, the complex was situated on the east side of kraton, in a location called Sawojajar, which is now known as Kampung Panembahan. Nowadays, almost all components of the complex can barely be found since the surrounding area has already become dense settlement. However, the remaining ones supported by textual and pictorial sources can be used to make a reconstruction of Kadipaten's architecture. Toponym related to the quarter can also be found around the location. This research aims to get the picture of the residence's environment in the past using historical-archeology approach. The result showed that Kadipaten was built in a spacious land with quite complete components, which has its own specificity in terms of layout and appearance. Its architecture suits both the role and status of the complex as a living quarter of crown prince, just a level in status below the Sultan's palace.
\end{abstract}

Keywords: Kadipaten, architecture, reconstruction, Yogyakarta

\begin{abstract}
Abstrak
Kadipaten atau kompleks hunian Pangeran Adipati Anom merupakan sub-kompleks penting dalam kawasan Kraton Yogyakarta. Saat ini, toponim Kadipaten dapat ditemukan di sebelah barat keraton. Meski demikian, beberapa laporan sejarah justru menunjukkan bahwa di masa sebelumnya kompleks tersebut berada di sisi timur keraton, tepatnya di suatu lokasi yang bernama Sawojajar yang kini dikenal sebagai Kampung Panembahan. Sebagian besar komponen kompleks tersebut kini hampir tidak dapat lagi diamati jejak fisiknya karena wilayah ini telah berkembang menjadi pemukiman padat. Meski demikian, sisa tinggalan yang didukung oleh sumber tekstual dan piktorial dapat menjadi bahan untuk merekonstruksi arsitektur Kadipaten. Toponim yang diduga berkaitan dengan kompleks Kadipaten juga ditemukan di wilayah sekitar. Penelitian ini bertujuan untuk memperoleh gambaran suasana kompleks Kadipaten di masa lalu dengan menggunakan kajian arkeologi kesejarahan. Hasil rekonstruksi arsitektur menunjukkan bahwa kompleks Kadipaten tidak hanya didirikan pada lahan yang luas, tetapi juga memiliki komponen penyusun yang terbilang lengkap. Tampilan, konstruksi, dan tata letak komponen dalam kompleks ini juga menunjukkan kekhususan tersendiri.
\end{abstract}


Hal ini sesuai dengan fungsi dan perannya sebagai hunian putra mahkota yang secara hierarki berada satu tingkat di bawah keraton.

Kata kunci: Kadipaten, arsitektur, rekonstruksi, Yogyakarta

\section{PENDAHULUAN}

Keraton, yang berdasarkan konsep kewilayahan dalam sistem pemerintahan Jawa merupakan pusat atau inti kawasan sekaligus ibu kota negara, tidak hanya menjadi tempat tinggal bagi raja dan kerabatnya. Kawasan ini juga dihuni golongan lain seperti pejabat pemerintah, pegawai istana, pelayan, dan pengawal (Knaap, 1999: 3). Golongan-golongan tersebut memiliki wilayah hidup masing-masing, berupa kompleks-kompleks bangunan ${ }^{1}$. Pangeran Adipati Anom atau putra mahkota merupakan salah satu golongan yang bertempat tinggal di dalam kompleks keraton. Hunian yang sekaligus juga menjadi "kantor dinas" putra mahkota tersebut disebut Kadipaten (Houben, 2002: 14). Kadipaten merupakan salah satu subkompleks penting di dalam Kraton Yogyakarta, selain Istana Air Tamansari (Knaap, 1999: $3)$.

Saat ini toponim Kadipaten di Kota Yogyakarta dapat dijumpai di sebelah barat keraton. Berbeda dengan kondisi sekarang, sebuah sketsa lama (lihat Gambar

1 Bentuk bangunan dalam lingkungan tersebut dapat dilihat, dikenali, dan dibedakan menjadi (a) bangunan tempat tinggal sultan berupa keraton dan fasilitas pendukungnya, seperti taman dan alun-alun; (b) bangunan-bangunan tempat tinggal milik pembesar dan pejabat keraton atau bangsawan, seperti bupati, adipati, senopati yang disebut dalem; (c) rumah-rumah biasa dan fasilitas urban bagi masyarakat umum(Mildawani, 1999: 40-41).
1) justru menunjukkan bahwa sebelumnya istana putra mahkota (prince's palace) tersebut terletak di sisi timur dalam beteng keraton yang diperpanjang $200 \mathrm{~m}$ ke utara. Kediaman dari Kanjeng Gusti Pangeran Adipati Anom (K.G.P.A. Anom) ${ }^{2}$ tersebut berada di lokasi yang bernama Sawojajar (Adam, 2003:31; Dinas Kebudayaan dan Pariwisata DIY, 2009:6). Laporan lain yang berasal dari awal abad ke-19 juga menyebut bahwa kompleks ini berupa lingkungan tertutup yang dilengkapi dengan sistem parit atau kolam yang berisi air (Bonneff, 1985: 31). Plengkung Tarunasura yang kini dikenal sebagai Plengkung Wijilan dan berada di timur laut beteng keraton merupakan gerbang masuk menuju Kadipaten (Carey, 2004: 75).

Sebagai subkompleks hunian perta-ma yang dibangun pada masa awal pendirian keraton, Kadipaten menjadi latar tempat terjadinya berbagai peristiwa penting pada masa Hamengku Buwono I hingga Hamengku Buwono III, antara tahun 1755-1816. Kompleks ini menjadi tempat diselenggarakannya pesta pernikahan cucu sultan (putri dari putra mahkota), diterimanya kunjungan residen Belanda, hingga diadakannya pertemuan rahasia antara Diponegoro dengan ayahandanya, Hamengku Buwono III yang ketika itu masih berstatus putra mahkota, menjelang perang melawan pasukan Inggris (Balai Penelitian Bahasa Yogyakarta, 1979: 81; Carey, 2011: 366). Kompleks ini sempat mengalami kerusakan parah akibat Perang

2 Nama kecilnya R.M. Sundoro, salah seorang putra dari Hamengku Buwono I (Sultan Mangkubumi), yang selanjutnya menjabat sebagai Hamengku Buwono II. 
Sepoy (Geger Sepehi) tahun 1812. Letaknya yang berada di timur keraton menjadikannya dekat dengan sarang meriam di benteng (Carey, 2011: 390). Pascaperang Jawa tahun 1830, kompleks ini berubah nama menjadi Dalem Panembahan

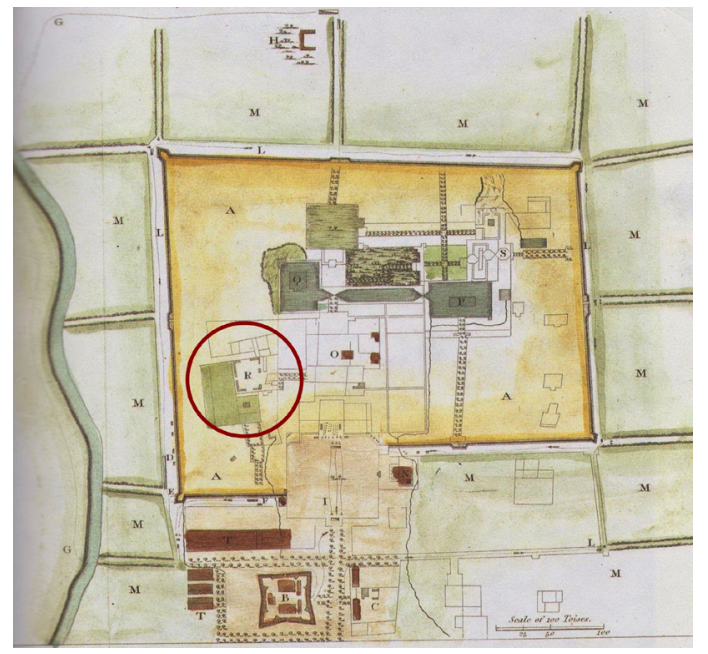

Gambar 1. Sketsa Kraton Yogyakarta $1812 \mathrm{M}$ Sketsa karya J. Wilbur Wright ketika pasukan Inggris menyerang keraton. Kadipaten diberi keterangan R (dalam lingkaran merah). Arah utara menghadap ke bawah.

(Sumber: Thorn, 2004: 186, dengan Modifikasi)

setelah ditempati oleh Gusti Panembahan Mangkurat yang merupakan salah satu putra Hamengku Buwono II (Sumintarsih, 2007: 62). Wilayah sekitar dalem ini berada selanjutnya dikenal sebagai Kampung Panembahan.

Pada masa selanjutnya, permukiman penduduk dan jaringan jalan di wilayah Kampung Panembahan dan sekitarnya bertumbuh dan berkembang dengan pesat. Hal ini berdampak pada semakin hilangnya komponen kompleks Kadi-paten yang tersisa. Satu dari sedikit tinggalan komponen kompleks yang relatif utuh dan nilainya cukup signifikan adalah Masjid Sela. Masjid yang didirikan pada $1787 \mathrm{M}$ ini memiliki gaya arsitektur dan konstruksi menyerupai bangunan di istana air Tamansari yang seluruh bagiannya mulai dari lantai, dinding hingga atap menggunakan bahan batu merah yang direkatkan dengan lime mortar (mortar kapur) tanpa kerangka besi (Dharmamulja, 1981: 25; Bonneff, 1985: 32).

Selain data artefaktual berupa sisa bangunan atau struktur, data non-artefaktual yang berupa toponim juga banyak dijumpai di wilayah Kampung Panembahan dan sekitarnya. Toponim biasanya diadaptasi dari tempat tinggal pangeran atau bangsawan penghuni dalem, atau abdi dalem berdasarkan keahlian atau pekerjaan, tapak petilasan, serta fenomena sosial baru yang muncul sebagai konsekuensi perkembangan kota. Toponim dapat pula menggambarkan asal, lapisan masyarakat, serta vegetasi yang berupa pepohonan tertentu yang ditanam di Kota Yogyakarta pada masa lalu (Sumintarsih dkk., 2007:59; Adrisijanti, 2007).

Sejauh yang diketahui, belum ada penelitian yang membahas kompleks Kadipaten di Kampung Panembahan secara khusus selain penyelidikan oleh Mintobudoyo pada tahun 1941. Penyelidikan tersebut menghasilkan gambar skalatis mengenai situasi tilas dalem K.G.P.A. Anom atau R.M. Sundoro pada tahun 1779 - 1791 yang berada di sisi timur beteng keraton. Sayangnya, penggambaran dua dimensi tapak kompleks beserta komponennya tersebut belum disertai dengan deskripsi lebih lanjut sehingga informasi yang diperoleh sangat terbatas. Berangkat dari pentingnya fungsi dan peran kompleks Kadipaten di masa lalu yang didukung keberadaan data arkeologis dan data sejarah, menarik untuk diketahui bagaimana arsitektur kompleks 
Kadi-paten pada masa lalu (1755 - 1830). Tujuan penelitian ini adalah memperoleh gambaran mengenai tatanan arsitektural kompleks Kadipaten yang terbentuk dari tampilan fisik dan keletakan komponen, berikut fungsinya masing-masing. Setelah mengetahui komponen selanjutnya ingin diketahui aspek-aspek dalam arsitektur Jawa pada komponen kompleks yang terdiri atas tampilan (gaya dan tata letak), cara membangun (konstruksi), serta gagasan (pemaknaan terhadap simbol).

Lingkup bahasan arsitektur dalam penelitian ini tidak terbatas pada bangunan saja, tetapi juga komponen kompleks lainnya, seperti halaman, jalan, tembok keliling, serta vegetasi. Tiap-tiap komponen tersebut sama pentingnya dan bersifat saling melengkapi untuk merekonstruksi kompleks Kadipaten ini. Rekonstruksi yang dimaksud dalam penelitian ini merupakan rekonstruksi asumtif di atas kertas. Oleh karena itu, upaya rekonstruksi arsitektur kompleks Kadipaten adalah sebatas pada hipotesis penggambaran, baik secara verbal maupun visual mengenai tatanan arsitektural kompleks tersebut dalam rentang waktu tertentu.

Penelitian ini menggunakan kajian arkeologi kesejarahan. Dokumen sebagai sumber data utama dalam penulisan sejarah pada dasarnya berkaitan dengan penggambaran dan pemahaman peristiwa di masa lalu. Maka, peran dokumen sama saja dengan objek material sebagai data arkeologi (Bahn, 2002: 38-39). Noel-Hume (1975) menyatakan bahwa dalam penelitian arkeologi kesejarahan ${ }^{3}$ (historical archaeology), data arkeologi dan data sejarah bersifat komplementer atau saling melengkapi. Data sejarah di sini dapat berupa data tekstual ataupun data piktorial

3 Pada praktiknya, kajian ini dapat menggunakan tinggalan budaya material untuk melakukan korfimasi atau menguji sumber literatur yang tersedia, atau sebaliknya, menggunakan sumber tertulis untuk menjelaskan tinggalan budaya material yang ada(Galloway, 2006: 42).

LOKASI PENELTTIAN

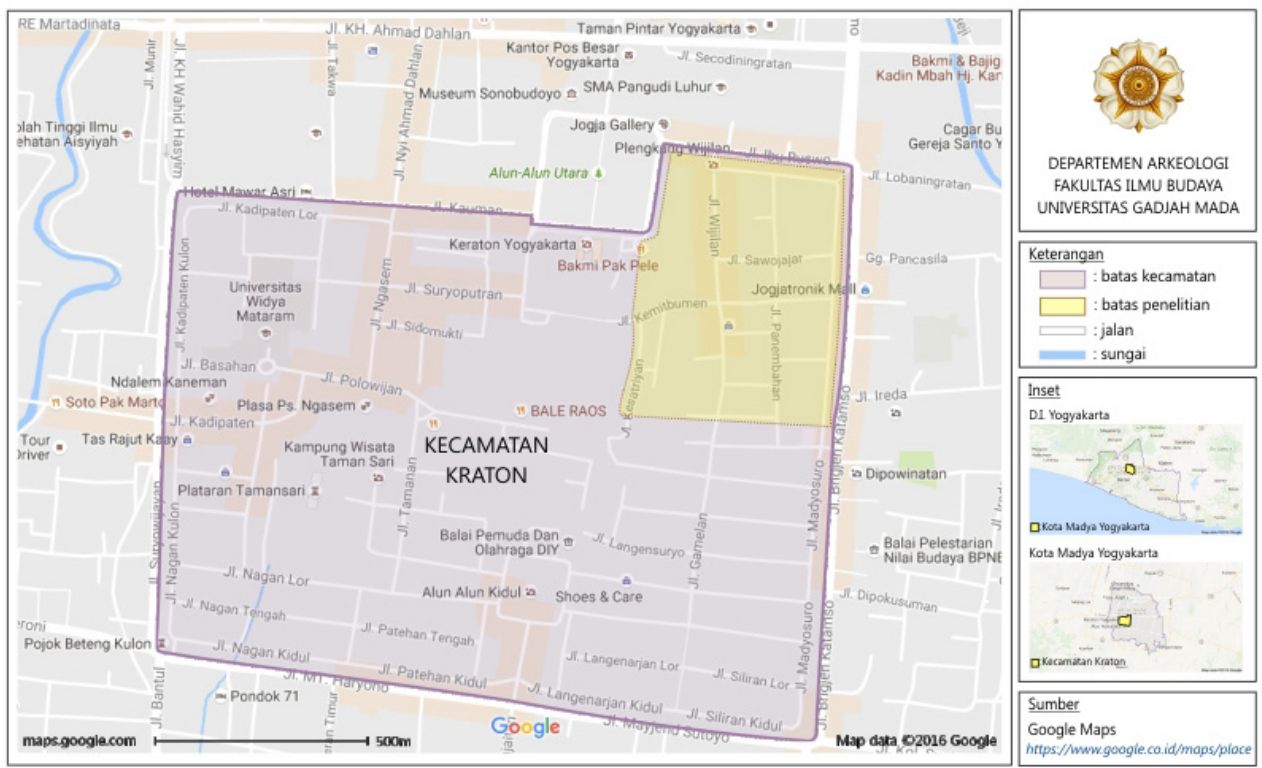

Peta 1. Lokasi penelitian mencakup Kampung Panembahan dan sekitarnya, yang berada di Kelurahan Panembahan, Kecamatan Kraton, Yogyakarta (Sumber: www.google.co.id/maps/place/, dimodifikasi oleh Retnaningtiyas) 
(Noel-Hume, 1975: 18-19).

Data primer dalam penelitian ini meliputi data artefaktual (terdiri atas bangunan, struktur, dan fitur), data non-artefaktual (toponim), serta data hasil wawancara. Data sekunder meliputi data tertulis yang terdiri atas naskah kuno babad dan naskah kuno nonbabad, buku, laporan penelitian, serta sumber piktorial yang terdiri atas peta lama, denah lama, foto lama, gambar teknis, dan citra satelit. Sebelum data primer dikumpulkan, terlebih dahulu dilakukan penentuan luas wilayah survei. Denah lama yang menggambarkan Kadipaten beserta komponennya diolah terlebih dahulu dengan citra satelit terbaru sehingga batas-batas dari kediaman putra mahkota tersebut dapat diketahui pada kondisi sekarang.

Babad yang dipilih dalam penelitian ini antara lain adalah Babad Mentawis 2 dan Babad Mentawis 3, Serat Babad Momana, serta beberapa kutipan serat dan babad lainnya yang berada dalam buku atau artikel $^{4}$. Naskah nonbabad atau dokumenter ${ }^{5}$ yang digunakan terdapat dalam buku Kraton Surakarta dan Yogyakarta 1769-1874. Laporan asing yang dirujuk terdapat dalam buku The Kraton: Selected Essays on Javanese Courts, trans-

4 Dokumen berasal dari koleksi G.P. Rouffaer yang tersimpan di KITLV Leiden, Belanda dengan kode Or 265 yang biasa disebut $J a$ vaansche Copijen. Sebagian besar dokumen yang disalin berasal dari abad ke-19, yang tertua berangka tahun 1769 sedangkan yang termuda dari tahun 1874 .

5 Artikel-artikel tersebut dimuat dalam jurnal Djawa yang dipublikasikan oleh Java Instituut di Yogyakarta selama kurun waktu 20 tahun, yakni 1921-1941. lation series 28 terbitan KITLV Press berisikan alih bahasa beberapa artikel Belanda yang ada hingga akhir periode kolonial pada 1930-an. Sementara peta dan denah lama yang dijadikan acuan adalah peta koleksi perpustakaan Koninklijk Instituut voot Taal-, Land-en Volkenkunde (KITLV) dalam bentuk digital, yakni peta Kraton Yogyakarta c.1833 dan Peta Kota Yogyakarta c.1872, Denah Patilasan Pasanggrahan Tamansari dan Pulo Gedong 1758-1812 Yogyakarta, serta denah tilas dalem Kanjeng Gusti Pangeran Adipati Anom, R.M. Sundoro pada tahun 17791791.

Selain data primer dan data sekunder, pada penyusunan rekonstruksi digunakan pula data pembanding. Bahan analogi dalam penelitian ini terdiri atas data pembanding stuktur dan data pemban-ding tampilan arsitektur. Dalem Mangkubumen dipilih sebagai data pembanding struktur karena sama-sama berfungsi sebagai hunian putra mahkota meskipun dibangun pada masa yang berbeda. Data pembanding tampilan arsitektur menggunakan bangunan-bangunan yang semasa dengan kompleks Kadipaten. Bangunan-bangunan tersebut merupakan bangunan yang sama-sama berfungsi sebagai fasilitas pendukung keraton yang banyak dibangun pada masa awal berdirinya Kraton Yogyakarta, seperti bangunan-bangunan dalam kompleks Tamansari, Panggung Krapyak, dan Masjid Agung.

\section{DALEM SEBAGAI RUMAH TRADISIONAL JAWA}

Rumah tinggal tradisional Jawa pada dasarnya tidak terbatas pada bangunan rumah saja, tetapi termasuk halaman 
dan lingkungan sekitarnya (Ronald, 1997: 273). Desain arsitekturnya berupa lingkungan buatan yang dikelilingi oleh pagar yang tersusun atas berbagai komponen, mulai dari sekelompok unit bangunan dengan fungsi berbeda, halaman luas, hingga vegetasi yang ditanam di sekeliling rumah. Seetiap komponen tersebut memiliki fungsi yang multiguna (Sunarmi, Guntur, \& Utomo, 2007: 46-47) dan bersifat saling melengkapi. Tatanan dan sifat ini juga berlaku bagi dalem, yang menurut Ronald (1984) merupakan salah satu wujud bangunan berarsitektur tradisional Jawa yang mempunyai konsep penataan lingkungan, bangunan, dan tata ruang yang baku (Mildawani, 1999: 64).

Kartodirjo (1993) dan Handoyotomo (1996) menyatakan bahwa tipologi dalem biasanya merupakan miniatur istana raja, baik bentuk maupun tata ruangnya, berupa suatu kompleks tempat tinggal luas dengan halaman depan yang juga luas sebagai miniatur alun-alun (Mildawani, 1999: 65-66). Sebagai kompleks hunian bagi putra mahkota atau calon raja, kompleks Kadipaten memiliki kekhususan jika dibandingkan dengan dalem lainnya. Kelengkapan, tata letak komponen, dan corak arsitektur kompleks ini dibuat mirip dengan keraton (Yuniastuti, Wibowo, \& Sukirman, 2014: 97-98).

Dalem biasanya terdiri atas rumah utama (dalem ageng) dan rumah depan (pendhapa), serta rumah-rumah lain yang memfasilitasi keperluan sehari-hari. Komponen penyusun kompleks dalem lainnya adalah cepuri, regol, gandhok, seketheng, dan los. Tapak dalem tersebut umumnya terletak pada lahan seluas 2000 $-3000 \mathrm{~m}^{2}$. Kompleks bangunan berada di bagian tengah lahan tersebut, dengan tapak massa bangunan utamanya membujur memanjang dengan orientasi utaraselatan (Mildawani, 1999: 68). Sebagai wujud arsitektur tradisi, Sedyawati (1999) menjabarkan bahwa kerangka deskripsi kajian sebuah dalem dapat dibagi menjadi enam kelompok, yakni (1) ragam bangunan, (2) fungsi, (3) penggunaan, (4) makna simbolik, (5) struktur morfologis, dan (6) konstruksi (Sedyawati, 1999: 176).

\section{HASIL DAN PEMBAHASAN}

Data artefaktual berupa bangunan, struktur, dan fitur yang dijumpai saat ini terkonsentrasi di wilayah RW 011 dan RW 012 Panembahan. Beberapa di antaranya yang cukup signifikan adalah Masjid Sela yang beralamat di PB II/329, RT 042, RW 011; rumah Ibu Siti Suprapti di PB II/31, RT 045, RW 012; gapura bentar (split gate) yang berada kurang lebih $150 \mathrm{~m}$ di selatan Plengkung Wijilan. Selain itu, terdapat pula sisa-sisa pagar tembok geometris dengan ketebalan 5-100 cm dan tinggi $2 \mathrm{~m}$ atau lebih yang tersebar di antara rumah-rumah warga. Semuanya tampak menggunakan konstruksi yang sama, yakni susunan bata berplester dengan ornamentasi profil lipit, $\mathrm{ikal} /$ volut,

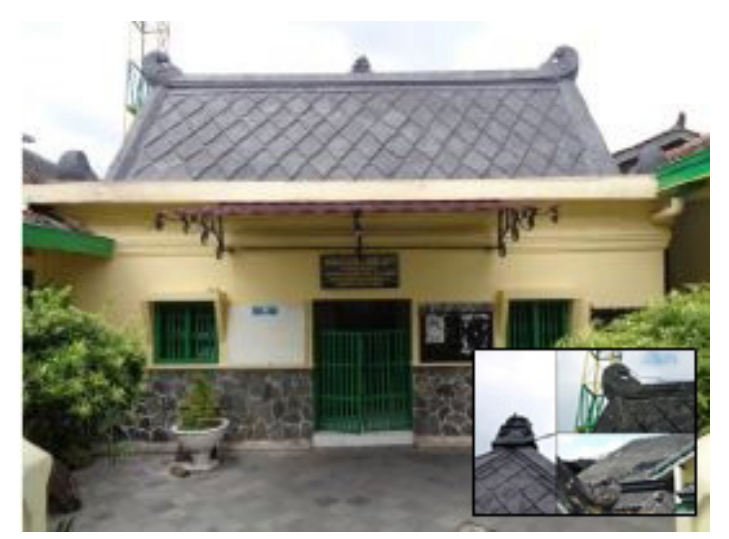

Gambar 2. Masjid Sela (Sumber: Dokumen Retnaningtiyas, 2017) 
hiasan bentuk sayap, motif sirap pada permukaan atap, hingga mahkuta di puncak atap (pada bangunan).

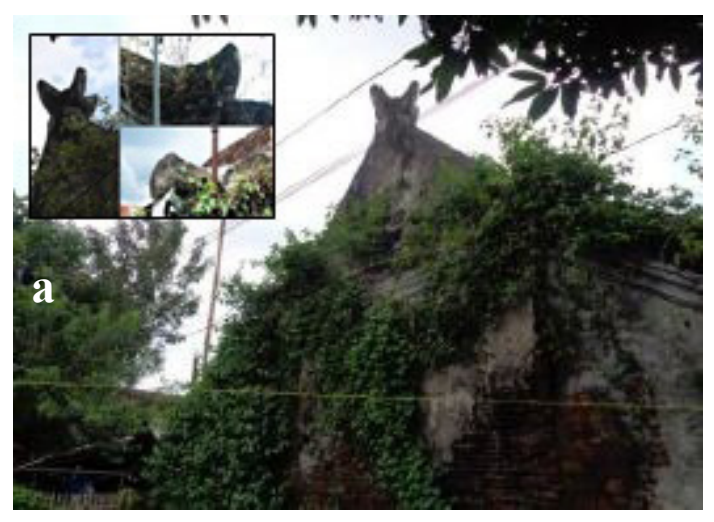

Gambar 3. Rumah Ibu Siti Suprapti

(Sumber: Dokumen Retcnaningtiyas, 2017)

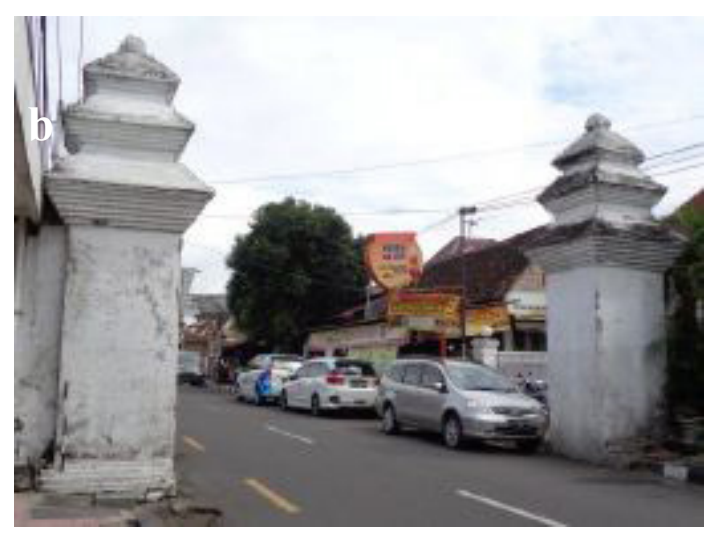

Gambar 4. Gapura Bentar atau Gapura Putih (Sumber: Dokumen Retnaningtiyas, 2017)

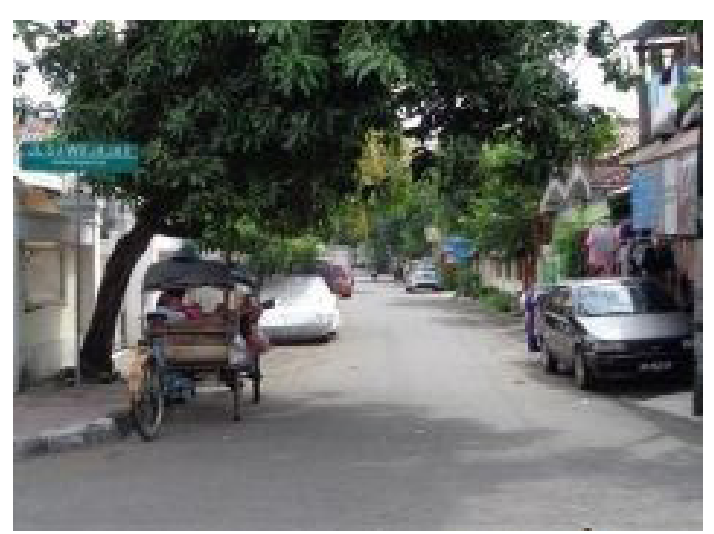

Gambar 5. Jalan Sawojajar

(Sumber: Dokumen Retnaningtiyas, 2017)

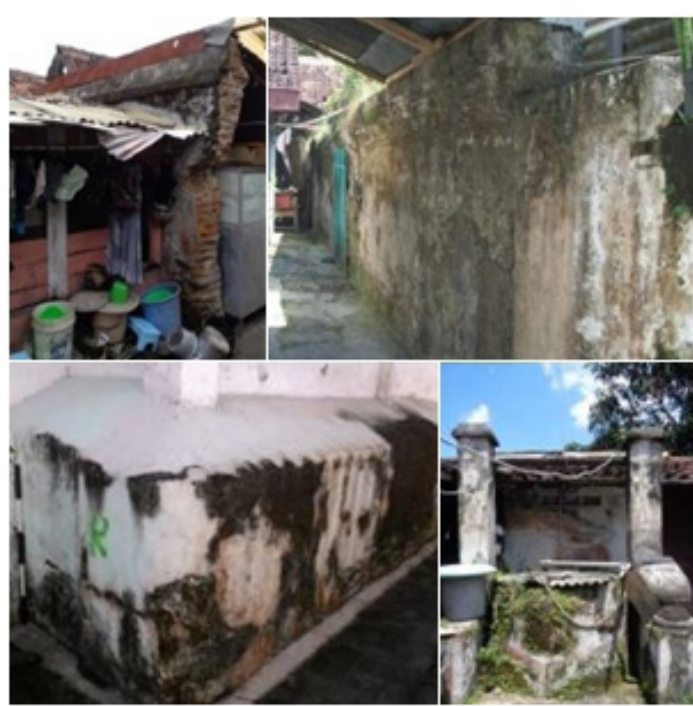

Gambar 6. Sisa Struktur dan Fitur yang Tersebar di Kampung Panembahan dan Sekitarnya (Sumber: Dokumen Retnaningtiyas, 2017)

Sementara nonartefaktual yang berupa toponim adalah Sawojajar yang saat ini menjadi nama sebuah jalan berorientasi timur-barat di Kampung Mangunegaran, Kelurahan Panembahan (Retnaningtiyas, 2017).

Rekonstruksi kompleks Kadipaten dilakukan dengan melakukan silang informasi yang diperoleh dari data primer, data sekunder, dan data pembanding. Silang informasi ditujukan agar informasi yang tidak ditemukan di lapangan dapat ditelusuri pada data sekunder dan data pembanding. Melalui silang informasi dari ketiga data tersebut, diketahui bahwa kompleks Kadipaten setidaknya memiliki bagian-bagian penyusun kompleks sebagai berikut.

\section{- Cepuri dan Seketheng}

Cepuri atau tembok keliling kompleks berupa struktur pagar tembok geometris yang membentang timur-barat dan utara- 
selatan. Denah lama menggambarkan bahwa kompleks Kadipaten dilengkapi dengan pagar keliling dan pagar pembatas halaman. Laporan yang berasal dari abad ke-19 juga menyebutkan bahwa kompleks Kadipaten dikelilingi oleh tembok yang tebal dan tinggi yang sangat kuat. Terkait penggunaannya di masa lalu, pagar tembok dengan ketebalan $80-100 \mathrm{~cm}$ dan ketinggian lebih dari $2 \mathrm{~m}$ kemungkinan merupakan pagar tembok keliling yang menjadi batas kompleks Kadipaten, sementara pagar tembok yang lebih tipis dan tidak terlalu tinggi merupakan tembok pembatas atau seketheng antar-halaman di dalam kompleks tersebut.

\section{- Regol}

Regol atau pintu gerbang kompleks berupa Plengkung Tarunasura dan gapura bentar. Keduanya berada di sisi utara di kompleks Kadipaten sehingga dapat dikatakan bahwa akses masuk utama menuju kompleks adalah melalui utara. Plengkung Tarunasura merupakan akses masuk pertama menuju ke kompleks Kadipaten yang berada di sisi paling utara dan langsung berbatasan dengan lingkungan di luar kawasan keraton. Selanjutnya, jika ingin masuk lebih dalam ke kompleks Kadipaten, ditemui gapura berbentuk bentar. Dalam naskah dokumenter yang menceritakan tata cara pelaksaanaan grebeg tahun 1812 - 1814, disebutkan bahwa gapura bentar tersebut ber-nama Sawojajar (karena terletak di lokasi tempat pohon sawo berjajar) dan menjadi tempat naiknya putra mahkota ke atas kendaraan untuk menuju ke alun-alun utara. Dalam denah lama, terlihat bahwa di sisi barat dan timur gapura bentar terdapat pacaosan yang menjadi tempat abdi dalem melakukan tugas jaga.

\section{- Gledhegan}

Gledhegan merupakan jalan khusus menuju kompleks Kadipaten. Panjang gledhegan dapat diukur dari jalan utama terdekat hingga ke gerbang kompleks tersebut. Pada kompleks Kadipaten, panjang gledhegan diukur dari Plengkung Tarunasura sebagai pintu gerbang yang langsung berbatasan dengan jalan di luar kawasan keraton hingga gapura bentar di sebelah selatannya. Saat ini plengkung dan gapura bentar berjarak sekitar $160 \mathrm{~m}$ sehingga panjang gledhegan kompleks Kadipaten pada masa lalu juga mencapai $160 \mathrm{~m}$.

\section{- Latar}

Latar atau halaman kompleks Kadipaten kemungkinan terdiri atas halaman depan, halaman belakang, dan halaman samping. Pembagian halaman terlihat dari komponen bangunan atau vegetasi yang berada di halaman tersebut. Halaman depan kompleks Kadipaten dapat diketahui melalui keberadaan regol atau gerbang utama serta vegetasi yang berupa pohon sawo. Pohon sawo ${ }^{6}$ merupakan salah satu jenis vegetasi yang biasanya ditanam di halaman depan rumah pangeran atau bangsawan atau di sebelah kanan dan kiri pendhapa. Keberadaan halaman samping dan halaman belakang dapat diketahui melalui denah lama yang meng-

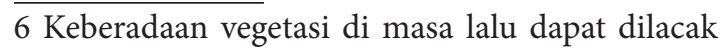
melalui toponim Sawojajar yang dapat berarti 'pohon sawo yang berjajar?. 
gambarkan dalem para sentana dan kebun buah. Pada halaman samping biasanya didirikan bangunan tempat tinggal untuk keluarga bangsawan (sentana), sementara halaman belakang biasanya menjadi kebun buah-buahan yang pilihannya lebih bebas tanpa ketentuan(Ikaputra, 1995: 78, 86).

\section{- Bangsal}

Bangsal merupakan bangunan berstruktur terbuka tanpa dinding. Bangsal dapat memiliki berbagai nama dan bentuk sesuai dengan fungsinya. Bangunan pendhapa yang ada dalam kompleks dalem biasanya berupa bangsal. MeskiPUN jejak bangunan yang mengindikasikan bangsal belum ditemukan di lapangan, sebuah laporan asing menyatakan bahwa pendhapa (reception pavilion) dari kompleks Kadipaten telah dipindahkan oleh Hamengku Buwono VI ke Dalem Kadipaten (saat ini Dalem Mangkubumen) ketika ia masih berstatus putra mahkota. Selain itu, naskah kuno, baik yang berupa babad maupun nonbabad, juga menyebutkan komponen kompleks Kadipaten yang disebut dengan banjar andhap. Banjar andhap di Kadipaten biasanya disebutkan bersamaan dengan sawojajar, yang seperti disebutkan sebelumnya dapat mengindikasikan halaman depan kompleks tersebut.

Pada data pembanding di Dalem Mangkubumen, komponen banjar andhap merupakan bangunan berjenis bangsal yang berbentuk joglo dan konstruksinya menggunakan tiang penyangga dan rangka atap dari kayu. Bangunan ini berada di halaman depan atau berada di sisi selatan di Dalem Mangkubumen (Albiladiyah,
1991: 15). Dengan menggu-nakan data pembanding, diperoleh kemungkinan bahwa banjar andhap yang ada di kompleks Kadipaten juga berupa bangsal dan berada di halaman depan. Banjar andhap disebutkan dalam naskah kuno, baik babad maupun nonbabad, sebagai tempat berkumpulnya para pengiring Pangeran Adipati Anom, salah satunya ketika diadakan pernikahan cucu sultan di Kadipaten.

Terkait penggunaannya di masa lalu, salah satu naskah kuno doku-menter menyebutkan bangsal sebagai tempat para pangeran dan bupati menghadap putra mahkota di Kadipaten. Dalam denah lama Mintobudoyo, komponen dengan keterangan paseban digambarkan di halaman depan. Paseban dapat diartikan sebagai 'balai penghadapan' atau 'tempat untuk menghadap'. Jika demikian, kemungkinan yang dimaksud dengan bangsal dalam naskah tersebut adalah bangsal paseban atau bangunan berstruktur terbuka yang digunakan sebagai tempat menghadap. Naskah juga menyebutkan bahwa ketika berada di bangsal penghadapan, para pangeran menghadap di sebelah utara dan selatan, sementara bupati dan bawahannya menghadap di barat. Jika disilangkan dengan informasi yang ada di denah lama, paseban digambarkan memiliki panggung di sebelah baratnya. Maka, dugaan bahwa paseban tersebut menghadap ke timur dengan panggung tempat putra mahkota menerima tamu Kadipaten menjadi kuat.

Sementara itu, fungsi bangunan pendhapa yang berada di kompleks Kadipaten pada masa lalu dapat dirunut dalam data sejarah. Pem-baringan jenazah 
Ratu Ageng (ibu dari Hamengku Buwono II) yang diiringi dengan upacara kerajaan dilaksanakan di Kadipaten pada Oktober 1750 (Carey, 2011: 97). Pada masa yang lebih lanjut, upacara pernikahan cucu Hamengku Buwono I juga dilaksanakan di kompleks ini. Dalam rumah tradisional Jawa, upacara seremonial seperti pembaringan jenazah dan pernikahan di rumah tradisional Jawa lumrahnya diselenggarakan di pendhapa. Oleh karena itu, meskipun tidak disebutkan secara spesifik tempat pelaksanaan-nya, diduga kedua acara ini juga dilakukan di pendhapa kompleks Kadipaten. Seperti halnya pada dalem secara umum, pendhapa kompleks ini kemungkinan juga dilengkapi dengan pringgitan.

\section{- Gedong}

Gedong merupakan bangunan berstruktur tertutup dengan dinding dari tembok. Dalam denah lama Mintobudoyo digambarkan bahwa di dalam kompleks Kadipaten terdapat komponen yang diberi keterangan sebagai griya tablegan, yang ke-mungkinan sama dengan gedong karena tableg dapat berarti tanggul sehingga griya tablegan merupakan bangunan yang dibuat dengan cara ditanggul (dinding tembok). Sama seperti bangsal, gedong juga dapat memiliki bentuk dan nama bangunan yang bermacam-macam sesuai dengan fungsinya.

Pada denah lama pula digambarkan dalem para sentana berada di sebelah barat kompleks Kadipaten. Berdasarkan temuan di lapangan, bangunan yang diduga dahulu merupakan bagian dari gugusan gedong keputren juga berada di sebelah barat kompleks. Jika dibandingkan dengan yang ada di Dalem Mangkubumen, bangunan tempat tinggal bagi para kerabat disebut gedong ijem dan berada di sebelah timur (Widyatsari, 2002: 129). Dengan orientasi dalem utara-selatan, baik di kompleks Kadipaten maupun Dalem Mangkubumen, bangunan gedong sebagai tempat tinggal kerabat berada di halaman samping.

\section{- Prabayeksa}

Prabayeksa merupakan dalem ageng dalam kompleks Kadipaten. Meskipun jejak bangunan ini belum dapat ditemukan di lapangan, denah lama menggambarkan bahwa dalem ageng yang diberi keterangan sebagai dalem K.G.P.A. Hamengkunegara tersebut berdenah persegi panjang dan berada di halaman belakang di dalam kompleks. Sama seperti dalem ageng pada umumnya, penggunaan praba-yeksa di masa lalu adalah sebagai bangunan tempat tinggal dari Pangeran Adipati Anom. Naskah kuno juga menyebutkan bahwa prabayeksa atau rumah besar di Kadipaten tersebut pernah diperbaiki pada tahun 1765 M. Sebagai data pembanding, prabayeksa di Dalem Mangkubumen juga memiliki denah persegi panjang dan dindingnya terbuat dari susunan bata. Atapnya berbentuk joglo dengan bahan penyusun atap dari sirap yang konstruksinya disangga delapan tiang saka guru dengan umpak batu (Adityo, 2011: 36).

Sebagai bangunan utama di dalam kompleks Kadipaten, prabayeksa tentu akan memiliki ukuran bangunan yang paling luas dan konstruksi yang paling kompleks, yakni bentuk joglo. Dalem ageng biasanya berupa bangunan 
berdinding yang berdenah persegi sehingga ruangnya bersifat tertutup. Jika gedong keputren di Kadipaten menggunakan bata berplester sebagai konstruksi dindingnya serta rangka kayu dan susunan sirap sebagai konstruksi atapnya, prabayeksa juga sangat mungkin menggunakan bahan tersebut.

\section{- Masjid}

Masjid Sela terletak di sebelah barat di dalam kompleks Kadipaten dan kemungkinan juga berada di halaman samping. Selain Masjid Sela, ada pula masjid umum dengan kolam keliling yang digambarkan dalam denah lama. Meskipun sisa tembok masjid saat ini hanya tinggal sedikit, sketsa lama tahun 1812 menunjukkan bahwa di lokasi yang sama terdapat struktur berupa kolam berbentuk U. Kedua masjid berada di sebelah barat dalam kompleks Kadipaten. Pada Dalem Mangkubumen yang menjadi data pembanding, masjid juga berada di sebelah barat kompleks tersebut.Terkait penggunaannya di masa lalu, masjid umum merupakan tempat peribadatan bagi publik yang ber-kunjung ke Kadipten, sementara Masjid Sela merupakan tempat peribadatan yang khusus digunakan oleh penghuni kompleks tersebut kala itu, yakni Pangeran Adipati Anom dan keluarganya.

\section{- Pekiwan}

Pekiwan berada di halaman belakang samping kiri atau sebelah barat daya di kompleks Kadipaten. Pekiwan terdiri atas sumur yang berasosisasi dengan kamar mandi.

\section{- Komponen Lainnya}

Meskipun tidak digambarkan dalam denah lama Mintobudoyo, istilah seperti tanjunganom dan panepen beberapa kali disebutkan dalam naskah kuno. Panepen yang berarti tempat untuk beristirahat disebutkan sebagai tempat pangeran berkumpul untuk menunggu pangeran adipati. Naskah juga menyebutkan istilah pengrawit tanjunganom. Pengrawit berasal dari kata rawit yang dapat berarti 'rumit' atau 'berhubungan dengan halhal yang halus, lembut'. Pengrawit merupakan istilah yang biasa digunakan untuk menyebut sekumpulan orang yang memainkan gamelan untuk mengiringi suatu acara. Dalam kompleks keraton, terdapat bangsal pengrawit yang dahulu digunakan sebagai tempat sultan melantik para pepatih dalem. Tanjunganom dalam naskah diaso-siasikan dengan sawojajar dan banjar andhap, yang keduanya berada di halaman depan dari kompleks Kadipaten.

Selain komponen berupa bangunan dan struktur, terdapat pula komponen berupa vegetasi. Kompleks Kadipaten memiliki vegetasi yang antara lain terdiri atas pohon sawo (biasanya berjenis sawo kecik) serta pohon buah-buahan, seperti rambutan dan duku. Dalam sketsa lama tahun 1812, digambarkan jajaran pohon di sepanjang gledhegan dan halaman paling depan dalam kompleks Kadipaten. Pohon tersebut diidentifikasi sebagai pohon sawo karena adanya istilah sawojajar, baik yang berada dalam naskah kuno maupun sebagai toponim saat ini. Dalam Denah Patilasan Pasanggrahan Tamansari dan Pulo Gedong 1758-1812 Yogyakarta, kebun buah rambutan dan duku digambarkan 
di halaman belakang atau di sisi selatan kompleks Kadipaten.

Melalui penjabaran di atas, terlihat bahwa komponen kompleks Kadipaten menggunakan tipe atap yang bervariasi, mulai dari tipe kampung pada bangunan gedong, serta limasan dan tajug pada bangunan masjid. Meskipun tidak lagi ditemukan jejaknya, kemungkinan dahulu komponen pendhapa dan dalem ageng/prabayeksa kompleks Kadipaten menggunakan tipe atap limasan atau joglo, sama seperti yang dijumpai di Dalem Mangkubumen. Atapnya dari susunan sirap atau diberi motif sirap Dalam hal ragam hias, variasi ornamentasi yang digunakan pada komponen kompleks Kadipaten terdiri atas profil lipit, pilaster, volut/ikal, hiasan sayap, dan mahkota. Ragam hias tersebut merupakan perpaduan antar Islam, serta pengaruh asing. Ragam hias yang demikian banyak pula diterapkan pada bangunan yang semasa, antara lain di Tamansari.

Bangunan dan struktur yang ada di Kadipaten menggunakan bahan bata dan kayu. Pada bangunan berupa gedong, baha: bata digunakan sebagai penyusun konstruksi dinding, sementara bahan kayu digunakan sebagai penyusun konstruksi atap (baik sebagai rangka maupun penutupnya), serta kusen jendela dan pintu. Konstruksi pagar keliling juga terbuat dari

7 Sirapmerupakan kepinganpapan tipis-tipis yang biasanya terbuat dari bahan kayu besi atau kayu ulin dan digunakan sebagai penutup atap.Pada bangunan yang atapnya terbuat dari susunan bata berplester (seperti bangunan-bangunan di Tamansari), motif sirap dicetak pada permukaan plesteran atap sisi luar. susunan bata, yang kemungkinan dipilih karena sifat konstruksinya yang kuat. Jika dilihat pada data pembanding, bangunan berupa bangsal di kompleks Kadipaten ke-mungkinan juga banyak menggunakan bahan kayu sebagai konstruksi penyusunnya, baik pada tiang maupun atap.

Selain dalam kompleks Kadipaten, bata dan kayu sebagai bahan konstruksi bangunan juga memang banyak digunakan pada bangunan-bangunan yang dibuat pada masa awal berdirinya keraton. Hal ini dapat dirunut dalam data sejarah, yang menyebutkan bahwa bahan-bahan yang akan digunakan untuk pelaksanaan pembangunan di kawasan keraton ketika itu (termasuk Tamansari dan Segaran Pulo Gedong) merupakan sumbangan dari seluruh rakyat dan bupati, termasuk dari mereka yang berada di daerah-daerah mancinegara sebagai bentuk gotongroyong seluruh lapisan masyarakat ${ }^{8}$

Konstruksi dengan bahan bata direkatkan dengan spesi tanpa campuran semen, melainkan terbuat dari bahan kapur dan pasir, kemudian dicampur dengan cairan dari legen atau nira. Susunan bata terse'jut kemudian diberi lapisan plester. Sebagai bandingan, bangunan-bangunan di Tamansari yang konstruksinya serupa dengan komponen di kompleks Kadipaten juga menggunakan bahan bata yang disusun dengan perekat spesi dan diberi plesteran. Ketebalan dinding dapat bervariasi, bergantung jenis bangunan dan fungsinya (sebagai pagar pembatas halaman atau sebagai dinding rumah, dsb.). Susunan

8 Lihat.: (Serat Rerenggan Kraton, alih aksara oleh Aryono., 1981). 
dinding bata mengikuti pola selang-seling. Plesteran yang tebalnya dapat berkisar antara 2--5 $\mathrm{cm}$ berfungsi sebagai pembalut pasangan bata terhadap ke-ausan dan kerusakan susunan bata (Tim Penyusun, 1996: 140-141).

Komponen Kadipaten, memiliki berbagai fungsi, baik secara individu maupun sebagai satu kesatuan kompleks. Fungsi pertama adalah fungsi praktis Kadipaten sebagai hunian sekaligus "kantor" putra mahkota. Maka, selain terdapat komponen yang digunakan untuk menampung kegiatan privat dan domestik (seperti prabayeksa/dalem ageng, dalem sentana, keputren, masjid, dan pekiwan), ada pula komponen yang digunakan untuk menampung kegiatan publik dan seremonial (seperti pendhapa, paseban, panepen, dan banjar andhap). Selain itu, ada pula komponen yang memiliki fungsi praktis sebagai bentuk pertahanan, yakni cepuri dan regol. Tembok yang tinggi dan tebal menimbulkan kesan defensif pada kompleks itu sendiri. Dua lapis regol atau pintu gerbang menunjukkan dua lapis penjagaan. Data sejarah mengungkapkan bahwa plengkung dilengkapi dengan fasilitas penjagaan dengan keberadaan jagang atau parit di depannya serta persenjataan berupa meriam, sementara gapura bentar dilengkapi dengan pacaosan di kedua sisinya.

Fungsi sosial terlihat dari tampilan fisik dan kelengkapan komponen penyusun serta tata ruangnya. Mengenai tampilan arsitektur, komponen kompleks Kadipaten menggunakan bahan bata, kayu jati, dan sirap (atau motif sirap). Groneveldt menyatakan bahwa pada abad XV penggunaan atap sirap hanya diperbolehkan untuk kalangan istana atau dengan kata lain hanya orang yang memiliki hubungan dekat dengan raja yang diperbolehkan menggunakannya (Groneveldt, 1960: 87). Selain sirap, bahan batu, atau bata untuk bangunan dan pagar juga tidak boleh digunakan oleh pihak di luar kalangan istana (Wirjomartono, 2009: 257). Jika demikian, penggunaan bahan juga terkait pada fungsi sosial untuk menunjukkan status kompleks Kadipaten sebagai hunian putra mahkota.

Beberapa komponen dalam kompleks Kadipaten merupakan komponen yang umum ditemui pada rumah tradisional Jawa (khususnya milik pangeran dan bangsawan). Meski demikian, beberapa komponen lainnya hanya ditemukan pada kompleks Kadipaten. Salah satunya adalah paseban, yang merupakan tempat tamu Kadipaten menghadap putra mahkota untuk melakukan sembah. Menurut Errington, putra mahkota merupakan satusatunya petinggi keraton selain sultan yang berhak menerima sembah dari para pejabat keraton dan bangsawan elite (Errington, 1982: 90). Komponen selanjutnya yang juga menunjukkan fungsi sosial adalah gledhegan. Panjang gledhegan jika dikaitkan dengan keletakannya (di dalam atau di luar beteng keraton) dapat menunjukkan luas lahan keseluruhan dan kepemilikan teritori kompleks oleh seorang bangsawan (Ikaputra, 1995). Gledhegan kompleks Kadipaten dengan panjang mencapai $150 \mathrm{~m}$, termasuk kategori panjang bagi dalem yang berada di jeron beteng, mengindikasikan bahwa kompleks tersebut berperan penting pada masanya dan dimiliki oleh bangsawan golongan tinggi. 
Melalui banyaknya pagar tembok pembatas di kompleks Kadipaten, terlihat adanya suatu pembagian halaman ruang di dalam kompleks tersebut. Santosa menyatakan bahwa pembagian ruang halaman biasanya mencerminkan fungsi halaman tersebut, baik sebagai area publik maupun area privat (Santosa, 1997: 30). Pada dalem dengan status dan peran yang lebih tinggi, pemisahan area yang satu dengan area lainnya melalui seketheng yang berlapis-lapis mengindikasikan perbedaan tingkat kepentingan bangunan (Widyatsari, 2002: 129). Hal ini dapat dilihat pada Dalem Mangkubumen yang pembagian ruang menimbulkan stratifikasi halaman di dalam kompleks menjadi empat area, yakni (1) area publik; (2) area semi-publik; (3) area semiprivat; dan (4) area privat (Adityo, 2011: 146). Semakin rumit pembagian ruang, semakin rumit pula stratifikasi ruang yang ada. Stratifikasi ruang yang kompleks dapat menunjukkan bahwa dalem tersebut memiliki status sosial yang tinggi.

\section{SIMPULAN}

Hasil rekonstruksi arsitektur kompleks Kadipaten (lihat Lampiran) dalam penelitian ini menambah dan merevisi informasi yang ada pada denah lama karya Mintobudoyo. Pada denah yang dihasilkan pada tahun 1941 tersebut, tapak Kadipaten digambarkan beserta komponennya yang terdiri atas plengkung, pacaosan, masjid umum, sawojajar, paseban, dalem ageng, dalem para sentana, masjid sela, panggung, kebun buah, serta bangsal dan griya tablegan. Melalui kelengkapan sumber data (data arkeologis, data sejarah, serta data pembanding) yang digunakan dalam penelitian ini, diketahui bahwa secara lebih lengkap kompleks putra mahkota yang berada di timur keraton tersebut juga memiliki komponen lainnya, seperti cepuri, seketheng, gledhegan, gapura bentar (gapura Sawojajar), bangsal banjar andhap, panepen, pendhapa, prabayeksa, keputren, dan pekiwan. Selain itu, diketahui pula bahwa sawojajar merupakan istilah yang digunakan untuk merujuk lokasi di kompleks Kadipaten yang ditanami pohon sawo, tepatnya di sepanjang gledhegan dan halaman depan.

Selain kelengkapan dan keletakan komponen, penelitian ini juga menghasilkan gambaran mengenai tampilan fisik, penggunaan di masa lalu, serta fungsi komponen-komponen tersebut. Secara struktur, kompleks Kadipaten memiliki kesamaan dengan dalem pangeran dan bangsawan pada umum-nya. Pembedanya adalah komponen penyusun struktur yang digunakan pada kompleks Kadipaten lebih lengkap. Berdasarkan tampilan fisik, keleng-kapan, fungsi, serta tata letak komponen, terlihat bahwa kompleks Kadipaten ini memiliki peran penting dan status yang tinggi pada masanya. Hal ini tentunya terkait dengan fungsi dan kedudukan kompleks tersebut sebagai

"rumah dinas" bagi putra mahkota, yang dalam struktur organisasi keraton berada satu tingkat di bawah sultan. Dengan kata lain, kompleks Kadipaten berada satu peringkat di bawah keraton sebagai hunian raja sehingga menjadi salah satu subkompleks kawasan keraton yang penting pada masanya. 


\section{DAFTAR PUSTAKA}

Adityo, D. H. (2011). Perubahan Fungsi dan Konstruksi Bangunan di Kompleks Dalem Mangkubumen. Universitas Gajah Mada.

Albiladiyah, S. I. (1991). Dalem Mangkubumen Kodya Yogyakarta dan Kompel Makam Girigondo Temon Kulonprogo. In Seri Peninggalan Sejarah Daerah Istimewa Yogyakarta (pp. 121-168). Yogyakarta: Balai Kajian Sejarah dan Nilai Tradisional.

Bahn, P. G. (2002). The Definitive Guide Archaeology. Sidney: Weldon Owen Publishing.

Balai Penelitian Bahasa Yogyakarta. (1979). Babad Mentawis 3. Jakarta: Departemen Pendidikan dan Kebudayaan, Proyek Penerbitan Buku Bacaan dan Sastra Indonesia dan Daerah.

Bonneff, M. (1985). La Mosquée de pierre (Masjid Sélo) de Yogyakarta. Archipel, 30(1), 31-38.

Carey, P. (2004). Asal Usul Perang Jawa: Pemberontakan Sepoy dan Lukisan Raden Saleh, edisi terjemahan (Terjemahan). Yogyakarta: PT LKiS Pelangi Aksara.

Carey, P. (2011). Kuasa Ramalan: Pangeran Diponegoro dan Akhir Tatanan Lama di Jawa, 1785-1855 (terjemahan). Jakaarta: KPG (Kepustakaan Populer Gramedia).

Dharmamulja, S. (1981). Mengenal Sekilas Bangunan Pesanggrahan Tamansari Yogyakarta. Yogyakarta: Departemen Pendidikan dan Kebudayaan Direktorat Sejarah dan Nilai Tradisional.

Errington, J. (1982). Speech in the Royal Presence: Javanese Palace Language. INDONESIA, 34(89-101).

Galloway, P. (2006). Material Culture and Text: Exploring the Spaces Within and Between. In M. Hall \& S. W. Silliman (Eds.), Historical Archaeology (pp. 42-64). Oxford: Blackwell Publishing, Ltd.

Groneveldt, W. (1960). Historical Notes on Indonesia \& Malaya, Compiled from Chinese Source. Jakaarta: CV Bhatara.

Houben, V. (2002). Keraton dan Kompeni: Surakarta dan Yogyakarta 1830-1870 (Terjemahan). Yogyakarta: Bentang Budaya.

Ikaputra. (1995). A Study on the Contemporary Utilization of the Javanese Urban Heritage and its Effect on Historicity: An Attempt to Introduce the Contextual Adaptability Into the Preservation of Historic Environment of Yogyakarta. Osaka University.

Knaap, G. (1999). Cephas, Yogyakarta: Photography in the service of the Sultan. Leiden: KITLV Press.

Mildawani, I. (1999). Kajian Sistem Penataan Lansekap Halaman Dalem Pangeran: Studi Kasus di Yogyakarta. Universitas Gadjah Mada. 
Noel-Hume, I. (1975). Historical Archaeology. New York: Alfred A. Knopf.

Retnaningtiyas, W. (2017). Rekonstruksi Arsitektur Kompleks Kadipaten di Kampung Panembahan, Kecamatan Kraton, Yogyakarta”. Skripsi Sarjana,. Universitas Gadjah Mada.

Ronald, A. (1997). Ciri-ciri Karya Budaya di Balik Tabir Keagungan Rumah Jawa. Yogyakarta: Universitas Atma Jaya.

Santosa, R. B. (1997). Omah: The Construction of Meanings in Javanese Domestic Settings., McGill University, Montreal.

Sedyawati, E. (1999). Arsitektur Bandingan untuk Kajian Hubungan Antarbudaya. In H. Chambert-Loir \& H. Ambary (Eds.), Panggung Sejarah: Persembahan kepada Prof. Dr. Denys Lombard, (pp. 176-185). Jakarta: EFEO, Puslit Arkenas, Yayasan Obor Nusantara.

Serat Rerenggan Kraton, alih aksara oleh Aryono. (1981). Jakaarta: Departemen Pendidikan dan Kebudayaan, Proyek Penerbitan Buku Sastra Indonesia dan Daerah.

Sumintarsih. (2007). Toponim Kota Yogyakarta. Yogyakarta: Dinas Pariwisata, Seni dan Budaya Kota Yogyakarta.

Sunarmi, Guntur, \& Utomo, T. P. (2007). Arsitektur dan Interior Nusantara Seri Jawa. Surakarta: ISI Surakarta.

Tim Penyusun. (1996). Laporan Studi Teknis Arkeologi Situs Tamansari Yogyakarta. Yogyakarta.

Widyatsari, S. (2002). Tata Ruang Rumah Bangsawan Yogyakarta. DIMENSI TEKNIK ARSITEKTUR, 30(2), 122-132.

Wirjomartono, B. (2009). Sejarah Kebudayaan Indonesia: Arsitektur. (G. Tjahjono, Ed.). Jakaarta: Rajawali Pers.

Yuniastuti, T., Wibowo, S. H., \& Sukirman. (2014). Mengungkap Sejarah Arsitektur Dalem Mangkubumen Yogyakarta Periode Tahun 1874-1949. Simposium Nasional RAPI XIII. Surakarta. 


\section{LAMPIRAN}

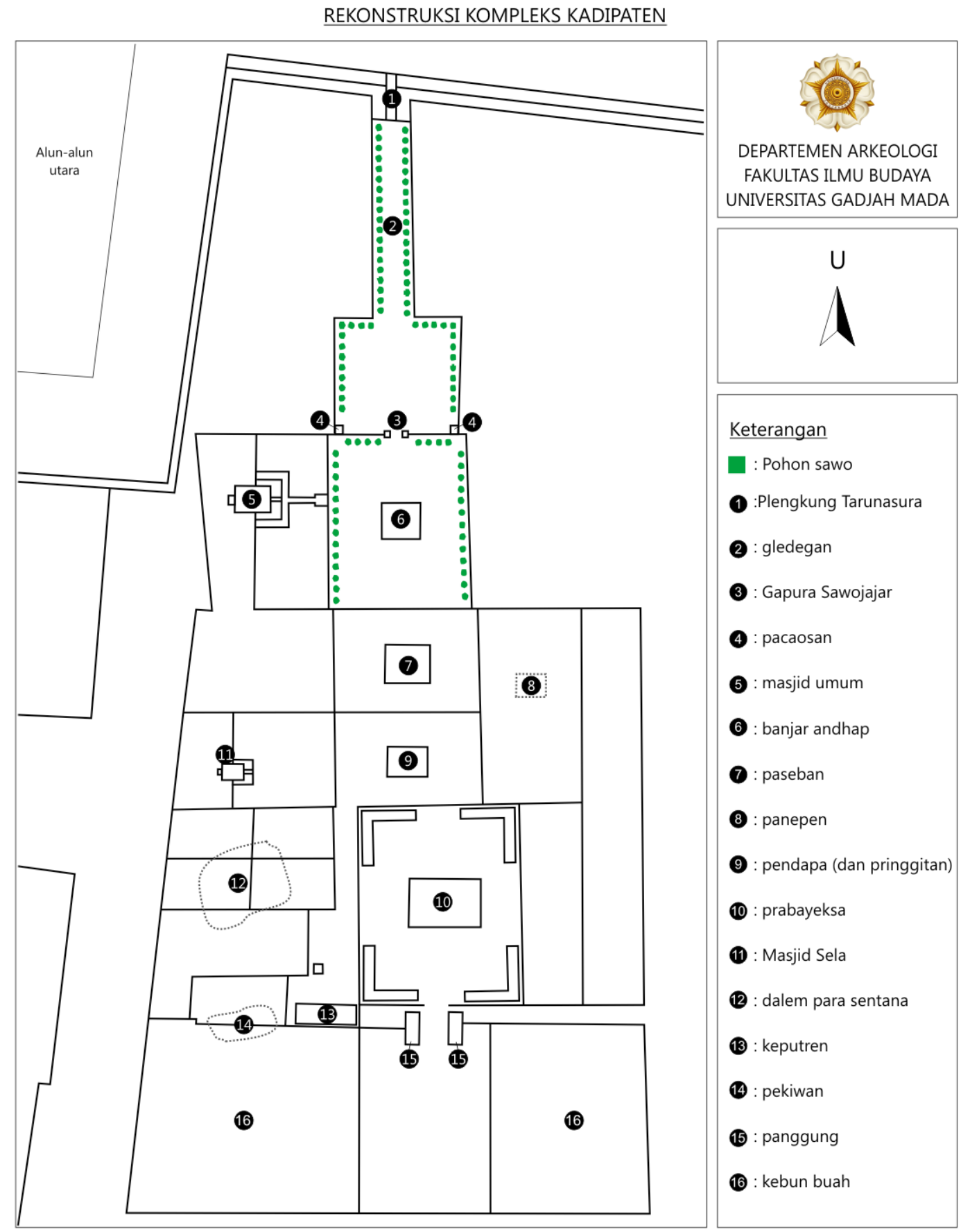

Gambar 7. Rekonstruksi Kompleks Kadipaten Rekonstruksi Komponen Kompleks Kadipaten Berdasarkan Penggabungan Informasi antara Data Arkeologis, Data Sejarah, dan Data Pembanding Diolah oleh Retnaningtiyas) 
PURBAWIDYa Q Vol. 7, No. 1, Juni 2018 35-52 